\title{
Features of the Value Orientations of Kazakhs Living Abroad
}

\author{
Farida Abubakirovna Sakhiyeva ${ }^{1}$, Sveta Kydyrbekovna Berdibayeva ${ }^{1}$, Gulzagira Makhatovna Atakhanova ${ }^{1}$, Aliya \\ Zhumabayevna Belzhanova ${ }^{1} \&$ Satybaldy Kydyrbekovish Berdibayev ${ }^{2}$ \\ ${ }^{1}$ Al-Farabi Kazakh National University, Almaty, Kazakhstan \\ ${ }^{2}$ Eurasian National University, Astana, Kazakhstan \\ Correspondence: Farida Abubakirovna Sakhiyeva, Al-Farabi Kazakh National University, Almaty, Kazakhstan.
}

Received: February 28, 2015 Accepted: March 20, 2015 Online Published: April 26, 2015

doi:10.5539/res.v7n6p317 URL: http://dx.doi.org/10.5539/res.v7n6p317

\begin{abstract}
The goal of our research is to study the value orientations of the Kazakh diaspora living abroad in Europe (for example, Germany) and Asia (for example, China). We identified similarities and differences in the structure of value spheres of foreign Kazakhs and the titular nation of KazakhstanThe results of the factor analysis allow us to conclude that the structure of valuable sphere of the titular nation of Kazakhstan and foreign Kazakhs multifaceted and characterized as certain similarities and differences. Foreign Kazakhs tend to value orientations, first of all, to find meaning in religion, belief, in fate, in spiritualityThey appreciate in their lives the possibility of change, a particular risk that probably prompted the move of their ancestors in China and Europe from KazakhstanIn addition, the foreign Kazakhs appreciate the sense of community and well-being that reflects their collective values that are manifested primarily in finding a sense of balance and in unison with themselves and others. Kazakhs living in Kazakhstan are characterized by individual value orientations. They focus mainly on self-realization and self-determination, especially when it comes to achieving social success. The most important value orientation is their family and material well-being, collective and social values are secondary for them.
\end{abstract}

Keywords: the titular ethnos of Kazakhstan, foreign Kazakhs, values, factor analysis, structure of value sphere, features of the value orientations of foreign Kazakhs, culture

\section{Introduction}

The goal of our research is to study the value orientations of the Kazakh diaspora living abroad in Europe (for example, Germany) and Asia (for example, China). Study of value orientations of the Kazakh diaspora living abroad, connected with a number of features, namely: the Republic of Kazakhstan is their homeland, and representatives of the Kazakh Diaspora are an integral part of the Kazakh people. Islam - the religion of Kazakh Diaspora, which is among the Turkic peoples, whose representatives for various reasons, live in Asia, Western Europe and America. Such factors as Kazakh-Jungar wars, Stalin's agrarian reform, actions of the tsarist government in relation to the peoples of Central Asia, the Soviet period, civil strife, and other historical events have an impact on the formation of foreign Kazakh Diaspora.

5 million of Kazakhs live in 43 countries according to the World Association of Kazakhs. $80.0 \%$ of them live in Uzbekistan, China and Russia. 2 million of Kazakhs living in Uzbekistan, about 2 million of Kazakhs living in China, 1 million of Kazakhs live in Russia, 83 thousand of Kazakhs living in Mongolia, 74 thousand of Kazakhs live in Turkmenistan, and 12 thousand of Kazakhs living in Turkey, 10 thousand of Kazakhs living in Kyrgyzstan, 5 thousand of Kazakhs live in Iran. In Europe: 180 families of Kazakhs live in France, 160 families of Kazakhs living in Germany, 51 family of Kazakhs live in Sweden, 20 families of Kazakhs living in Austria, 14 families of Kazakhs living in the United States, 150 families of Kazakhs live in Afghanistan, 15 families of Kazakhs living in Saudi Arabia, 5 families of Kazakhs living in Australia.

In this case, as noted by the World Association of Kazakhs, the number of Kazakh diaspora abroad for various reasons underestimated. According to the same organization 2 million of Kazakhs are willing to return to Kazakhstan. It has not yet found its implementation, primarily because of the lack of specific scientific and economic program supported by the implementation of this desire (Yermolaev, 2003).

The living conditions of foreign representatives of the Kazakh diaspora are largely dependent on the economic situation of the country in which they reside. Economic, political status of the Kazakhs and their socio-cultural environment are different in different countries of the world. Particular difficulties arise in matters of nationality 
and status of the Afghan diaspora (Khamitova, 2008).

The essential problem of Kazakhs abroad is the study of the Kazakh language, preservation of national culture, folk customs, traditions and implementation of education in their native language, which allowed us to talk about the relevance of the study of value orientations of Kazakhs living abroad, as the basis for the preservation of national culture (Blyumkin, 2001).

An essential part of the national policy of the Republic of Kazakhstan is the return of or almans to their historical homeland or to establish close relationships the titular nation of Kazakhstan representatives with the Kazakh diaspora abroad. One of the problems of national policy is to solution of the demographic problem as the current demographic situation in Kazakhstan is unstable, the population is decreasing every year, the birth rate is low, and representatives of other nationalities leave the country (Kasymova \& Niyazbekova, 1994).

In connection with the above, we have considered the problem of the study of ethnic and human values of the titular nation of Kazakhstan and representatives of the Kazakh diaspora abroad as one of the central problems of preservation and development of Kazakh national culture, traditions, customs and continuity of generations.

\section{Method}

We have developed a comprehensive package of psych diagnostic methods. These methods allow us to consider the similarities and differences of value orientations of the titular nation of Kazakhstan and representatives of the Kazakh diaspora living abroad. We used such methods as: a questionnaire of Schwartz (values questionnaire (VQ) of Schwartz) (Korzhakova, 2004; Schwartz \& Bilsky, 1987; Schwartz, Melech, Lehmann, Burgess, Harris, Owens, 2001), a technique of studying value orientations of $M$. Rokeach, method of diagnosis system of value orientations of Fantalova in modification of L. S. Kolmogorova and D. V. Kashyrskiy (Fantalova, 2002), modification of Kuhn's technique "Who am I?", an adapted version of the questionnaire of T. Schnell and P. Becker "Lebe-Life values and meanings" (Schnell \& Becker, 2006; Schnell \& Becker, 2007) author's adaptation in Kazakh language (Kline, 1994).

A questionnaire of Schwartz (values questionnaire (VQ) of Schwartz) is used to study the dynamics of changes in values in groups (cultures) due to changes in society and for the individual in connection with its problems of life. The questionnaire was developed by Schwartz in 1992 (Schwarz, 1992).Under the values S. Schwartz (Schwartz) meant "know" needs directly dependent on culture, the environment, the mentality of a particular society. The basis of the questionnaire of Schwartz is the theory that all values are divided into social and individual. Sh. Schwartz describes in his model 12 basic human values: enjoyment, achievement, social power, self-determination, stimulation, restrictive conformity, support traditions, social, security, maturity, social culture, spirituality.

In developing the questionnaire Schwartz used the technique of M. Rokeach, qualitatively modify, expand and improve its conceptual framework.

A technique of studying value orientations of M. Rokeach is now more common technique study of values, based on the direct ranking list of values. M. Rokeach distinguishes between 2 classes of values: the terminal - the belief that the ultimate goal of individual existence is worth it to seek; instrumental - the belief that a certain course of action or property of the person is preferred in any situation. This division corresponds to the traditional division into value-goals and values-means (Burlachuk, 2003; Bakhrakh-M, 2011).

The respondent imposed 2 lists of values (18 values in each). The respondent assigns each value ranking number in these lists.

Method of diagnosis of value orientations' system of E. B. Fantalova in modification of L. S. Kolmogorova and D. V. Kashyrskiy examines the system of value orientation and internal conflicts of personality (E. B. Fantalovain modification of L. S. Kolmogorova, Kashirskiy, 2002).

Multidimensional scaling procedure is the basis of this method. Paired comparison method is one way of multidimensional scaling. The subject is presented a list of areas of life. Then he compares pairs of fields of activity at the most important areas in first selection and availability of spheres in the second selection.

Serial number of the answer to the question "Who am I?" is interpreted as a response indicating national identity to the Kazakh diaspora in modification of Kuhn's technique "Who am I?" (Bakhrakh-M, 2011).

Interdisciplinary theory of evolution, which comes from the personal significance of existential thinking, feelings and actions, is the basis for the questionnaire "Lebe" aimed at the diagnosis of life values and meanings (T. Schnell and P. Becker (2007). Representatives of various social, cultural and religious backgrounds were interviewed when creating this questionnaire (Karandashev \& Schwartz, 2003). The theoretical basis is on a hierarchical construct of life values, which are implemented as meaning and as the main value manifested in the form of 
thoughts, feelings and actions (Korzhakova, 2006). The questionnaire includes 26 major scales that measure the values of life. All of them can be distributed over the 4 global dimensions: self-transcendence, self-development, order and community-being. The Fifth Dimension, considered independently of the values in life and giving information about the perceived meaning of life, is responsible for the meaningfulness or existential crisis (Schnell \& Becker, 2007) (name and values see on Table 1).

Table 1. Description of the scales of the questionnaire "Lebe" of T. Schnell, P. Becker

\begin{tabular}{|c|c|}
\hline Scale / Parameter & Explanation of the content of the scale \\
\hline \multicolumn{2}{|l|}{ Meaning of life } \\
\hline Meaningful & The extent to which private life is perceived as meaningful \\
\hline Crisis of meaning & The degree of experience of meaninglessness of life \\
\hline \multicolumn{2}{|l|}{ Transcendence-vertical } \\
\hline Severe & Finding meaning in religion and faith \\
\hline \multicolumn{2}{|l|}{ Religiousness } \\
\hline Spirituality & Finding meaning in the other reality, belief in fate (fatalism) \\
\hline \multicolumn{2}{|c|}{ Transcendence- - Horizontal } \\
\hline Social Activity & Finding meaning in the active concern for the common good and human rights \\
\hline Relationship with nature & Finding meaning in harmony with nature \\
\hline Knowledge of self & Finding meaning in search of yourself and understanding yourself \\
\hline Health & Finding meaning in the preservation and promotion of a healthy lifestyle \\
\hline Generative & Finding meaning in the interest of the younger generation and its education \\
\hline \multicolumn{2}{|l|}{ Self-realization } \\
\hline Challenge & Finding meaning in the search for a new, changes and risk \\
\hline Individualism & Finding meaning in personality and life potentials \\
\hline Power & Finding meaning in the struggle and domination \\
\hline Development & Finding meaning in the sense of purpose \\
\hline The Result & Finding meaning in the competence and success \\
\hline Freedom & Finding meaning in the sovereignty and self-determination \\
\hline Knowledge & Finding meaning in information and understanding in matters of understanding \\
\hline Creation & Finding meaning in the fantasy and the creative process \\
\hline \multicolumn{2}{|l|}{ Order } \\
\hline Tradition & Finding meaning in the prescribed manner. Verified and familiarity \\
\hline Pragmatism & Finding meaning in pragmatism and the particular application \\
\hline Morality & Finding meaning in the orientation in the fundamental norms and values \\
\hline Prudence & Finding meaning in checking and rationality \\
\hline \multicolumn{2}{|c|}{ Sense of community and well-being } \\
\hline Community & Finding meaning in human intimacy and friendship \\
\hline Pleasure & Finding meaning in humor and pleasure \\
\hline Love & Finding meaning in the romance and intimacy \\
\hline Wellness & Finding meaning in the well-being and enjoyment \\
\hline Care & Finding meaning in the care and willingness to help \\
\hline Awareness of life & Finding meaning in attentiveness and rituals \\
\hline Harmony & Finding meaning in the balance and unison with yourself and others \\
\hline
\end{tabular}

The study involved subjects aged from 20 to 60 years. The average age of the subjects is 42 years, 5 months. 
Sample of the titular nation of Kazakhstan is 103 subjects, sample of the Kazakhs living in China is 54 subjects, and sample of the Kazakh diaspora in Germany is 61 subjects. Total 218 representatives of Kazakh ethnos took part in the study. The experimental group consisted of representatives of the Kazakh diaspora living abroad (115 subjects), the control group consisted of representatives of the titular nation of Kazakhstan (103 subjects). The study involved 121 women and 97 men. Approximately equal proportions of men and women are observed in each of the samples of research (Yadov, 1995).

\section{Results}

We now turn to the results of the study. We consider the results of diagnostic of value orientations by each technique in experimental and control groups and compare the results for such statistical criteria as U-Mann-Whitney test and t-test for independent samples (Yermolaev, 2003).

Table 2. Results of statistical analysis of Schwartz's questionnaire by U-Mann-Whitney test

\begin{tabular}{|c|c|c|c|c|c|c|c|c|c|c|c|c|}
\hline \multirow{2}{*}{ Parameters } & $1 \mathrm{Sch}$ & $2 \mathrm{Sch}$ & 3Sch & $4 \mathrm{Sch}$ & $5 \mathrm{Sch}$ & 6Sch & $7 \mathrm{Sch}$ & $8 \mathrm{Sch}$ & 9Sch & $10 \mathrm{Sch}$ & $11 \mathrm{Sch}$ & $12 \mathrm{Sch}$ \\
\hline & 1Sch & $2 \mathrm{Sch}$ & $3 \mathrm{Sch}$ & $4 \mathrm{Sch}$ & $5 \mathrm{Sch}$ & 6Sch & $7 \mathrm{Sch}$ & $8 \mathrm{Sch}$ & 9Sch & $10 \mathrm{Sch}$ & $11 \mathrm{Sch}$ & $12 \mathrm{Sch}$ \\
\hline U-criterion & 40434043 & 45574557 & 41734173 & 45294529 & 43084308 & 40894089 & 44154415 & 45074507 & 40304030 & 41404140 & 37723772 & 42544254 \\
\hline$\rho \rho$ & .1818 & .9494 & .3131 & .8888 & .4949 & .2222 & .6767 & .8484 & .1717 & .2727 & .05 .05 & .4141 \\
\hline
\end{tabular}

As can be seen from Table 2, the experimental and control groups differ from each other only by one criterion, namely the criterion of "social culture". Qualitative analysis included in this parameter variables shows that between the titular nation of Kazakhstan and Kazakhs living abroad, the differences relate to variables such as the avoidance of debt, sense of unity with nature, indifference to worldly concerns, making their lives, avoiding extreme feelings and actions, modest, simplicity, protection of nature. According to the analysis of average ranks among foreign Kazakhs this criterion is less pronounced compared to the titular nation of Kazakhstan. The presence of only one statistical difference in the method of Schwartz says about the similarities of human values among the Kazakhs living in Kazakhstan and abroad. Let us now compare the diagnostic results by the method of E. B. Fantalova (Fantalova, Kolmogorova, \& Kashirskiy, 2002).

Table 3. Results of statistical analysis of E. B. Fantalova's questionnaire by U-Mann-Whitney test

\begin{tabular}{|c|c|c|c|c|c|c|c|c|c|c|c|c|c|}
\hline criterion & $\mathrm{f} 1$ & $\mathrm{f} 2$ & $\mathrm{f} 3$ & $\mathrm{f} 4$ & f5 & f6 & $\mathrm{f} 7$ & f8 & f9 & $\mathrm{f} 10$ & f11 & $\mathrm{f} 12$ & $\mathrm{R}$ \\
\hline U-criterion & 3807 & 4288 & 4045 & 3908 & 3728 & 4244 & 4214 & 4137 & 4055 & 3642 & 4037 & 4193 & 3503 \\
\hline Asymptotic-value & .13 & .78 & .37 & .21 & .09 & .69 & .63 & .50 & .37 & .04 & .29 & .60 & .02 \\
\hline
\end{tabular}

As can be seen from Table 3, we have identified differences in the criteria of "Freedom as independence in behavior and actions" and the criterion of "The discrepancy between the value and accessibility" between the subjects of the experimental and control groups. According to the analysis of the average rank of the table, these criteria are more pronounced in foreign Kazakhs compared to the titular ethnic groups of Kazakhstan. Perhaps this indicates that foreign Kazakhs higher value freedom as independence in behavior and actions compared to the titular ethnic groups of Kazakhstan, at the same time experiencing a large mismatch between values and their availability. Let us analyze the results of the methods of Kuhn and Lebe (Schnell \& Becker). 
Table 4a. Results of statistical analysis of methods of Kuhn and Lebe by U-Mann-Whitney test

\begin{tabular}{|c|c|c|c|c|c|c|c|c|c|c|c|c|c|c|c|c|}
\hline criterion & $\mathrm{NC}$ & $\mathrm{T}$ & $\mathrm{TV}$ & TG & SR & $\mathrm{O}$ & $\mathrm{CW}$ & $\mathrm{M}$ & $\mathrm{P}$ & $\mathrm{C}$ & $\mathrm{Pl}$ & $\mathrm{L}$ & W & $\mathrm{C}$ & $\mathrm{AL}$ & $\mathrm{H}$ \\
\hline U-criterio & 362 & 317 & 275 & 353 & 357 & 315 & 291 & 299 & 313 & 297 & 371 & 328 & 348 & 269 & 330 & 244 \\
\hline $\mathrm{n}$ & 3 & 0 & 1 & 2 & 8 & 3 & 8 & 2 & 4 & 4 & 6 & 3 & 0 & 3 & 2 & 9 \\
\hline $\mathrm{P}$ & .006 & .001 & .001 & .021 & .029 & .001 & .001 & .001 & .001 & .001 & .065 & .003 & .015 & .001 & .004 & .001 \\
\hline
\end{tabular}

Note. NC-nationality; T-transcendence; TV-Transcendence-vertical; TG-transcendence-horizontal; $\mathrm{SR}$ - self-realization; $\mathrm{O}$-order; $\mathrm{CW}$-Sense of community and well-being; $\mathrm{M}$-Morality; $\mathrm{P}$ - Prudence; C-Community; Pl-Pleasure; L-love; W-Wellness; C-care; AL-Awareness of life; H-harmony.

Table 4b. Results of statistical analysis of methods of Kuhn and Lebe by U-Mann-Whitney test

\begin{tabular}{|c|c|c|c|c|c|c|c|c|c|c|c|c|c|c|c|c|c|c|c|}
\hline criterion & M & $\mathrm{CM}$ & SA & SR & $\mathrm{RN}$ & KS & $\mathrm{H}$ & G & $\mathrm{S}$ & $\mathrm{C}$ & I & $\mathrm{P}$ & $\mathrm{D}$ & $\mathrm{R}$ & $\mathrm{F}$ & $\mathrm{K}$ & $\mathrm{Cr}$ & $\operatorname{Tr}$ & $\operatorname{Pr}$ \\
\hline U-criterion & 2884 & 3250 & 4433 & 2946 & 3659 & 3354 & 4260 & 3756 & 2962 & 3666 & 3296 & 3526 & 3722 & 3715 & 3521 & 3110 & 4131 & 4145 & 2679 \\
\hline$P$ & .001 & .003 & .961 & .001 & .047 & .006 & .630 & .082 & .001 & .049 & .004 & .021 & .068 & .065 & .020 & .001 & .421 & .442 & .001 \\
\hline
\end{tabular}

Note. M-meaningful; CM-crisis of meaning; SA-social activity; SR — severe religiousness; RN-relationship with nature; $\mathrm{KS}$ - knowledge of self; $\mathrm{H}$ - health; $\mathrm{G}$ - generative; $\mathrm{S}$ - spirituality; $\mathrm{C}$ — challenge; I-individualism; $\mathrm{P}$-power; D-development; $\mathrm{R}$ - the result; $\mathrm{F}$ - freedom; $\mathrm{K}$-knowledge; $\mathrm{Cr}$-creation; $\mathrm{Tr}$ - tradition; $\mathrm{Pr}$ - pragmatism.

As can be seen from Table $4 \mathrm{a}$ and $4 \mathrm{~b}$ there are many differences in values and sense of values found between the subjects of the experimental and control groups according to the methods of Kuhn and Lebe. Statistical differences were not identified only for 8 of the 34 parameters settings. The similarity in values was found on such parameters as: pleasure, social activity, health, generative, development, result, creation, tradition. We have identified a statistical difference in indicator of "nationality" by the method of Kuhn. Foreign Kazakhs, answering the question "Who am I?", rarely called themselves Kazakhs compared with the Kazakhs living in Kazakhstan or rank of their response was significantly higher compared with the similar rank response from representatives of the titular ethnos of Kazakhstan living in Kazakhstan (Bratus, 2002).

We consider the results of the comparison value orientations of the experimental and control groups by the method of M. Rokeach now.

Table 5a. Results of statistical analysis of M. Rokeach's method by T-Student's test

\begin{tabular}{|c|c|c|c|c|c|c|c|c|c|c|c|c|c|c|c|c|c|c|}
\hline Scale & 1 & 2 & 3 & 4 & 5 & 6 & 7 & 8 & 9 & 10 & 11 & 12 & 13 & 14 & 15 & 16 & 17 & 18 \\
\hline T-criterion & -1.34 & 0.72 & -3.65 & -0.82 & .46 & .89 & -.87 & 1.14 & -1.24 & -.50 & -.05 & -.38 & -.70 & 1.93 & -.23 & 1.26 & 1.00 & 1.02 \\
\hline Significance & .18 & .47 & .01 & .41 & .65 & .38 & .39 & .26 & .22 & .62 & .96 & .71 & .49 & .06 & .82 & .21 & .32 & .31 \\
\hline
\end{tabular}

Note. The terminal values: 1-active life (completeness and emotional richness of life); 2-practical wisdom (maturity of judgment and common sense, achieved by life experience); 3-health (physical and mental); 4 - interesting work; 5-the beauty of nature and art (the experience of beauty in nature and in art); 6-love (spiritual and physical intimacy with a loved one); 7-financially secure life (lack of financial difficulties); 8-availability good and faithful friends; 9- public recognition (the respect of others, collective, co-workers); 10 - cognition (the ability to expand education horizons, general culture, intellectual development); 11-Productive Life (fullest possible use of capabilities, powers and abilities); 12-development (work on yourself, permanent physical and spiritual perfection); 13 - entertainment (pleasant, not burdensome pastime, absence of the obligation); 14 - freedom (autonomy, independence in judgments and actions); 15-happy family life; 16 - the happiness of others (well-being, development and improvement of other people, of all nation, humanity as a whole); 17-creativity (the ability of creative activity); 18-self-confidence (internal harmony, freedom from internal contradictions and no doubts). 
Table 5b. Results of statistical analysis of M. Rokeach's method by T-Student's test

\begin{tabular}{lllllllllllllllllll}
\hline Scale & $\mathbf{1}$ & $\mathbf{2}$ & $\mathbf{3}$ & $\mathbf{4}$ & $\mathbf{5}$ & $\mathbf{6}$ & $\mathbf{7}$ & $\mathbf{8}$ & $\mathbf{9}$ & $\mathbf{1 0}$ & $\mathbf{1 1}$ & $\mathbf{1 2}$ & $\mathbf{1 3}$ & $\mathbf{1 4}$ & $\mathbf{1 5}$ & $\mathbf{1 6}$ & $\mathbf{1 7}$ & $\mathbf{1 8}$ \\
\hline T-score & -2.2 & -.7 & -.8 & -1.4 & -.3 & .4 & -1.7 & -.3 & 2.3 & -.6 & -1.9 & .9 & .3 & .5 & 2.0 & 2.1 & .00 & -2.1 \\
& 9 & 5 & 0 & 4 & 2 & 7 & 9 & 1 & 4 & 7 & 4 & 0 & 3 & 4 & 1 & 4 & & 9 \\
Significanc & $\mathbf{. 0 2}$ & .46 & .43 & .15 & .75 & .6 & $\mathbf{. 0 8}$ & .76 & $\mathbf{. 0 2}$ & .50 & $\mathbf{. 0 5}$ & .3 & .7 & .5 & $\mathbf{. 0 5}$ & $\mathbf{. 0 3}$ & 1.0 & $\mathbf{. 0 3}$ \\
$\mathrm{e}$ & & & & & & 4 & & & & & & 7 & 4 & 9 & & & 0 & \\
\hline
\end{tabular}

Note. Instrumental values: 1 - accuracy (cleanliness), the ability to keep in order the things, the order of affairs; 2-Education (good manners); 3-high demands (high demands on life and high aspirations); 4 - cheerfulness (humor); 5 - executive (discipline); 6 -independence (the ability to act independently, strongly); 7-intolerance of shortcomings in themselves and others; 8-education (breadth of knowledge, high general culture); 9-responsibility (sense of duty and ability to keep his word); 10 - rationalism (the ability to think logically and sensibly, make informed, rational decisions); 11-self-control (self-restraint, self-discipline); 12 - courage in defending their opinions, attitudes; 13 - a strong will (the ability to insist on his own, not to give in to difficulties); 14-tolerance (for the views and opinions of others, the ability to forgive others, their mistakes and errors); 15-liberality (the ability to understand another's point of view, respect the other tastes, customs, habits); 16-honesty (truthfulness, sincerity); 17-efficiency in the affairs (hard work, productivity in the work); 18 - sensitivity (diligence).

As can be seen from Tables $5 \mathrm{a}$ and $5 \mathrm{~b}$ there are statistically significant differences in value orientations by the method of M. Rokeach between subjects of experimental and control groups. These orientations are - two terminal values of health and freedom, and 7 instrumental values: accuracy, intolerance of shortcomings in themselves and others, responsibility, self-control, liberality, honesty and sensitivity.

Due to the large number of variables and data we decided to apply the procedure of factor analysis of data in order to reduce its dimension. We used the statistical software package SPSS 21.0 for statistical processing by factor analysis.

Processing was carried out by the method of principal components, was chosen Varimax rotation with Kaiser Normalization was chosen, considered factors with eigenvalues greater than one. Rotation in the case of 95 variables in the experimental sample Kazakhs living abroad required 61 iterations, the control group of Kazakhs living in Kazakhstan required 130 iterations (method of Schwartz 12 variables, method of M. Rokeach 36 variables, method of E. B. Fantalova 13 variables, and method of Lebe 34 variables).

As a result of factor analysis was established in the case of the experimental group of 28 new factors that explain in the aggregate more than $87.91 \%$ of the total variance, and 27 new factors in the case of the control group that explain more than $75.03 \%$ of the total variance, that is a good result. We analyzed the first factors 4 and 3 , respectively, whose information content exceeds $3.0 \%$ of the total variance.

We turn to the interpretation of the results now. We have identified the factor loadings of modulus greater than 0.4 in the data analysis. During interpretation the largest absolute factor load is allocated to each variable.

\section{Discussion}

The positive pole of the factor is interpreted on the basis of the positive pole of variables with the largest positive load and negative poles of the variables that have the most negative load. Accordingly, the negative pole of the factor corresponds to the negative pole of the variables with the highest positive load and the positive pole of the variables with the most negative load.

We summarize the work done and list the latent factors are discovered through the joint analysis techniques in descending order of their importance for the structure of valuable sphere of foreign Kazakhs (a questionnaire of Schwartz (values questionnaire (VQ) of Schwartz), a technique of studying value orientations of M. Rokeach, method of diagnosis system of value orientations of E. B. Fantalova in modification of L. S. Kolmogorova and D. V. Kashyrskiy, method of Lebe):

1) Sense of community and well-being, its basis is a sense of harmony and fulfillment.

2) Maturity, based on self-determination and stimulation.

3) Sense of transcendence is closely interrelated ewith feeling of deep religiosity.

4) Finding meaning in the search for new, for changes and risk in connection with the belief in fate. 
We summarize the work done and list the latent factors are discovered through the joint analysis techniques in descending order of their importance to the structure of the value sphere of Kazakhs living in Kazakhstan(a questionnaire of Schwartz (values questionnaire (VQ) of Schwartz), a technique of studying value orientations of M. Rokeach, method of diagnosis system of value orientations of E. B. Fantalova in modification of L. S. Kolmogorova and D. V. Kashyrskiy, method of Lebe):

1) Self-realization, assuming a greater role of a sense of community and well-being, individualism.

2) Self-determination and achievement of success.

3) Happy family life and financially secure life more important than active life and life maturity.

Thus, the results of the factor analysis allow us to conclude that the structure of valuable sphere of the titular nation of Kazakhstan and foreign Kazakhs multifaceted and characterized as certain similarities and differences.

\section{Conclusion}

The first four values, representing the most important characteristics of the structure of valuable sphere of Kazakhs living abroad, namely the sense of community and well-being, maturity, transcendence, based on religious, finding meaning in the search for new, in risk, faith in destiny suggest that prevail both collective and individual values that allow, first of all, to achieve a sense of community with others.

Foreign Kazakhs tend to value orientations, first of all, to find meaning in religion and faith, in destiny and spirituality. They appreciate in their life the opportunity to change and a particular risk, which probably prompted their ancestors moved to China and Europe from Kazakhstan. In addition, the foreign Kazakhs appreciate the sense of community and well-being that reflects their collective values that are manifested primarily in finding a sense of balance and in unison with yourself and others.

Kazakhs living in Kazakhstan are characterized, above all, by individual value orientations. They focus mainly on self-realization and self-determination, especially when it comes to achieving social success. For them, the most important value orientation is their family and material well-being, collective and social values in this case are secondary.

This result is explained by the historical events surrounding the life path of Kazakhs living abroad, and the Kazakhs living in Kazakhstan. Kazakhs living abroad are the National Minorities in Europe and China, which needs to be supported by their own ethnic group, so a sense of community, strongly expressed in the structure of their sphere of values, giving them a much-needed social support. Religiosity as the value of foreign Kazakhs remained as one of the main, unlike the Kazakhs living in Kazakhstan, because of the objective historical reasons, related to its ban in the Soviet period of formation and development of the Republic of Kazakhstan.

Kazakhstan is a young state and it's certainly has an impact on the values of the titular nation of Kazakhstan. The desires to express themselves, the desire to realize them, the desire to do everything possible for their family are absolute values of individual priorities. Perhaps, a sense of community, a sense of religiosity and harmony will also be one of the values-priorities, when economic, social and cultural situation in Kazakhstan largely stabilized.

Thus, we have identified the value orientations of foreign Kazakhs; we conducted a comparative analysis of the value orientations of Kazakh diaspora living abroad and in Kazakhstan. Factor analysis of the data allowed us to identify the structure of the value orientations of foreign Kazakhs. In further analysis we plan to compare the value orientations of foreign Kazakhs with the German settlers, who had previously lived in Kazakhstan.

\section{References}

Bakhrakh, M. (2011). Practical psychological testing (pp. 672-690). Moscow.

Blyumkin, V. A. (2001). The world of moral values (pp. 150-165). Moscow.

Bratus, B. S. (2002). Psychology and Psychoanalysis of nature (pp. 155-172). Moscow.

Burlachuk, L. F. (2003). Psychdiagnostics. In Textbook for High Schools Peter (pp. 309-352).

Fantalova, E. B., Kolmogorova, L. S., \& Kashirskiy, D. V. (2002). Method of diagnostic value orientations of the individual. Diagnostics of psychological culture of pupils: A practical guide for school psychologists (pp. 259-263). Moscow.

Fantalova, E. B. (2002). New methods of diagnosisin Clinical (pp. 177-217).

Karandashev, V. N., \& Schwartz, S. H. (2003). Technique for the study of the values of the individual (pp. 70-78). Moscow.

Kasymova, G. S., \& Niyazbekova, K. S. (2009). Spiritual and moral ideas of proto Kazakhs (pp. 51-59). Almaty. 
Khamitova, A. B. (2008). Problems of human values in Kazakh culture. Karaganda.

Kline, P. (1994). Reference design tests (an introduction to the design of psychometric) (pp. 283-289). Moscow.

Korzhakova, E. Y. (2006). Psychology of life orientation (pp. 370-384). Moscow.

Schnell, T., \& Becker, P. (2006). Personality and Meaning in Life. In Personalityand individual Differences (pp. 117-129). Germany.

Schnell, T. (2006). Ohne Sinn kein Glück? Zur Relativierung und Differenzierung des Zusammenhangs von Sinn und Neurotizismus (pp. 61-73). Germany.

Schnell, T., \& Becker, P. (2007). Fragebogen zu Lebensbedeutungen und Lebenssinn (pp. 53-58). Germany.

Schwartz, S. H., Melech, G., Lehmann, A., Burgess, S., Harris, M., \& Owens, V. (2001). Extending the cross-cultural validity of the theory of basic human values with a different method of measurement (pp. 519-542).

Schwartz, S. H., \& Bilsky, W. (1987). Towards a psychological structure of human values (pp. 550-562).

Schwarz, S. H. (1992). Universals in the content and structure of values: Theoretical advances and empirical tests in 20 countries. In Advances in Experimental Social Psychology (pp. 65-69). Germany.

Yadov, V. A. (1995). Case study: Methodology, program practices. Samara.

Yermolaev, O. (2003). Kazakhstan model of ethnic policy (pp. 92-96). Almaty.

\section{Copyrights}

Copyright for this article is retained by the author(s), with first publication rights granted to the journal.

This is an open-access article distributed under the terms and conditions of the Creative Commons Attribution license (http://creativecommons.org/licenses/by/3.0/). 